\title{
Field-Aligned Current Associated With a Distorted Two-Cell Convection Pattern During Northward Interplanetary Magnetic Field
}

\author{
L. ZHU, R. W. SCHUNK, AND J. J. SOJKA \\ Center for Atmospheric and Space Sciences, Utah State University, Logan
}

\begin{abstract}
A systematic study of the influence of the ionospheric conductance on the field-aligned current associated with a distorted two-cell convection pattem during northward interplanetary magnetic field (IMF) has been conducted. Our modeling results indicate that the NBZ current can be associated with the distorted two-cell convection for most of the ionospheric conductivity conditions. It is shown that the conductivity conditions related to the seasonal variation and the aurora activity can significantly influence the basic features of the field-aligned current associated with a distorted two-cell convection pattern. It is found that the increase of the field-aligned current in the polar cap during the summer is mainly due to the increasing contribution from the Pedersen current, and the increase of the field-aligned current in both the oval region and the evening-midnight sector during the active aurora period is mainly due to the increasing contribution from the Hall current. It is also found that the conductivity change related to the solar variation has its impact mainly on the intensity of a field-aligned current system instead of its pattem. On the basis of the modeling results it is suggested that the field-aligned current system observed by the Magsat satellite (Iijima and Shibaji, 1987) might imply a distorted two-cell convection pattern, and a fourcell convection pattem is most likely to occur when the direction of the IMF is due north or very close to the north.
\end{abstract}

\section{INTRODUCTION}

The high-latitude ionospheric convection is an essential element in many geophysical processes. The dependence of the ionospheric convection on the orientation of the interplanetary magnetic field (IMF), especially on the direction of the north-south component of the IMF, has been recognized for many years [Dungey, 1961; Russell, 1972]. Because of the strong correlation with auroral activity at high latitudes, most of the initial work was relevant to the cases in which the IMF had a southward component. However, with the continued observation of many unique dynamical features in the ionosphere the ionospheric convection and the related dynamics during the northward IMF have begun to draw more and more attention and interest. During periods of northward IMF, auroral arcs are observed in the polar cap [Lassen, 1972; Ismail and Meng, 1982; Murphree et al., 1982], and at times, arcs cross the whole polar cap in the day-night direction occur and form an auroral pattern called "theta aurora" [Frank et al., 1982]. The features of the polar cap arcs have been studied by many authors both observationally [Gussenhoven, 1982; Hardy et al., 1982; Burke et al., 1982] and theoretically [Kan and Burke, 1985; Chiu, 1989]. The features of the ionospheric convection during northward IMF deviate greatly from those during southward IMF. Convection patterns in the form of distorted two-cell [Heppner and Maynard, 1987], four-cell [Burke et al., 1979], and even three-cell [Potemra et al., 1984; Reiff and Burch, 1985] configurations have been proposed for the ionospheric convection during northward IMF.

The viewpoint favoring a four-cell ionospheric convection pattern for northward IMF had prevailed for a long period. It had been shown that reconnection between a northward IMF

\footnotetext{
Copyright 1991 by the American Geophysical Union.

Paper number 91JA01950.

148-0227/91/91JA-01950\$05.00
}

and the open field lines poleward of the cusp region can produce sunward convection in the polar cap [Russell, 1972; Maezawa, 1976; Burch et al., 1985]. Adding the two cells inside the polar cap due to reconnection to the two cells outside the polar cap due to viscous interactions in the lowlatitude boundary layer yields a four-cell ionospheric convection pattern [Burke et al., 1979]. Observational support for the four-cell pattern is principally the sunward convection across the central polar cap observed by the S3-2 and Magsat satellites [Burke et al., 1979; Iijima et al., 1984] and by ground magnetometers [Maezawa, 1976]. However, since Heppner and Maynard [1987] published the distorted two-cell ionospheric convection patterns based on the DE 2 electric field data, the issue of ionospheric convection during a northward IMF has become a controversial one. One of the advantages of the DE 2 satellite is that its orbits cover a much wider range of magnetic local time than either the S3-2 or Magsat satellites. Therefore its data are more suited to elucidating the flow patterns in the dayside region and can give a more complete picture of the global convection pattern. The DE 2 electric field data indicated that strong east-west flows occur in the dayside region, which is in contrast with the features in four-cell convection patterns, and the observed convection pattern appeared to be better represented by a distorted two-cell pattern for a northward IMF [Heppner and Maynard, 1987].

When the IMF-dependent convection maps to the ionosphere, the associated field-aligned currents can vary significantly for various ionospheric conductivity conditions. A study of the field-aligned current distribution associated with a four-cell convection pattern for various ionospheric conductivity conditions has been conducted by Rasmussen and Schunk [1987]. However, the field-aligned current distribution associated with a distorted two-cell convection pattern can be significantly different from that associated with a four-cell pattern. While focusing on the functional representation of 
the Heppner-Maynard convection model and its comparison with the Heelis et al. [1982] convection model, Rich and Maynard [1989] displayed a pair of field-aligned currents inferred from the Heppner-Maynard distorted two-cell convection pattern. However, a systematic study of the fieldaligned current distribution associated with the distorted twocell convection pattern for various ionospheric conductivity conditions (solar variation, auroral activity, and seasonal variation) has not been conducted to date.

Another important issue concerns the NBZ current system. The NBZ current is a typical current system existing in the polar cap during northward IMF [Iijima et al., 1984; Iijima and Shibaji, 1987]. By using the field-aligned current distribution inferred from the Magsat satellite data [Iijima and Shibaji, 1987], which had the NBZ current feature, and a conductivity model, Rasmussen and Schunk [1988] found that the resulting convection can be very similar to the distorted two-cell pattern deduced from the DE 2 satellite data [Heppner and Maynard, 1987], but this interpretation was not unique owing to the lack of data on the dayside. On the other hand, by using the distorted two-cell convection pattern [Heppner and Maynard, 1987] and a conductivity model [Hardy et al., 1987; Rich et al., 1987], Rich and Maynard [1989] claimed that in the resulting field-aligned current distribution there was no indication of a NBZ current. Whether or not the NBZ current is associated with the distorted two-cell convection pattern is an essential element in the controversial four-cell versus two-cell issue.

The purpose of this work is to conduct a systematic study of the influence of the ionospheric conductance on the fieldaligned current distribution associated with the distorted twocell convection pattern during northward IMF, to provide a complete set of the characteristic ionospheric current system for different ionospheric conductivity conditions, to study the closure of the field-aligned current and the ionospheric Hall and Pedersen currents, and to elucidate how the variation of the ionospheric conductivity condition influences the current closure. The results shed some light on the controversial fourcell versus two-cell issue.

\section{MATHEMATICAL FORMULATION}

The large-scale ionospheric convection is driven by the magnetospheric convection that originates from the solar wind-magnetosphere interaction, which, in turn, is controlled by the interplanetary environment. The communication between these two convections occurs via a field-aligned current system. Whenever there is a significant change of the interplanetary environment, the whole coupled magnetosphere-ionosphere system undergoes an internal adjustment in an effort to achieve a new steady state. For instance, when the IMF turns southward, the enhanced magnetospheric convection caused by the enhanced dayside reconnection tends to accelerate the ionosphere and the ionosphere, in turn, acts as a load and decelerates the magnetosphere. Such a process is essentially a transient process. As long as the interplanetary environment remains stable for a long period, the whole M-I system, sooner or later, will approach a steady state, depending on the ionospheric load. In this work we assume the ionosphere has approached such a steady state and that there are no more time-dependent interactions between the magnetosphere and ionosphere.
Specifically, we study the influence of the various ionospheric conductivity conditions on the ionospheric current system assuming a given steady state distorted two-cell convection pattern for northward IMF conditions [Heppner and Maynard, 1987].

\subsection{Basic Equations}

The ionosphere is treated as a two-dimensional slab with an integrated conductivity. The relationship between the ionospheric electric field $\mathbf{E}$ and the ionospheric heightintegrated current density $\mathbf{i}$ can be expressed by Ohm's law,

$$
\mathbf{i}=\sigma \cdot \mathbf{E}
$$

where

$$
\sigma=\left(\begin{array}{cc}
\Sigma_{\theta \theta} & \Sigma_{\theta \phi} \\
\Sigma_{\phi \theta} & \Sigma_{\phi \phi}
\end{array}\right)
$$

is a $2 \times 2$ tensor representing the anisotropic height-integrated conductivity in the ionosphere in which $\theta$ denotes colatitude and $\phi$ denotes longitude. The elements of the tensor are

$$
\Sigma_{\theta \theta} \simeq \frac{\Sigma_{p}}{\sin ^{2} I} \quad \Sigma_{\theta \phi} \simeq \frac{\Sigma_{H}}{\sin I} \quad \Sigma_{\phi \theta}=-\Sigma_{\theta \phi} \quad \Sigma_{\phi \phi} \simeq \Sigma_{p}
$$

where $I$ is the inclination angle of the geomagnetic field with respect to the horizontal ionosphere, $\Sigma_{H}$ and $\Sigma_{P}$ are the heightintegrated Hall and Pedersen conductivities, respectively.

Since we have assumed the whole physical process is in a steady state, the current continuity equation can be expressed as

$$
\nabla \cdot \mathbf{i}=j_{\|} \sin I
$$

where $j_{\|}$is the field-aligned current density and

$$
\sin I=\frac{2 \cos \theta}{\left(1+3 \cos ^{2} \theta\right)^{1 / 2}}
$$

By inserting equation (1) into equation (4) we obtain

$$
\nabla \cdot(\sigma \cdot \mathbf{E})=j_{\|} \sin I \text {. }
$$

Since we have used the steady state assumption, which leads to $\nabla \times \mathbf{E}=0$, equation (6) can be rewritten in terms of the potential $\Phi$ as,

$$
\nabla \cdot(\sigma \cdot \nabla \Phi)=-j_{\|} \sin I,
$$

When the field-aligned current associated with a plasma convection pattern flows into the ionosphere, it must connect to the ionospheric Hall and/or Pedersen currents. For different convection patterns and various ionospheric conductivity distributions the closure feature can be significantly different. To analyze the closure characteristics of the field-aligned and horizontal currents associated with a distorted two-cell convection pattern for various conductivity conditions, one needs to decompose equation (6). In a polar coordinate system, equation (6) can be rewritten as

$$
\frac{1}{\sin I} \nabla \cdot(\sigma \cdot \mathbf{E})=j\|H+j\| P 1+j\|P 2=j\|
$$


where

$$
\begin{aligned}
& j_{\| H}=\frac{1}{\sin I}\left[E_{\phi} \frac{\partial \Sigma_{\theta \phi}}{\partial r}+\frac{E_{\theta}}{r} \frac{\partial \Sigma_{\phi \theta}}{\partial \phi}\right] \\
& j_{\| P 1}=\frac{1}{\sin I}\left[E_{\theta} \frac{\partial \Sigma_{\theta \theta}}{\partial r}+\frac{E_{\phi}}{r} \frac{\partial \Sigma_{\phi \phi}}{\partial \phi}\right] \\
& j_{\| P 2}=\frac{1}{\sin I}\left[\Sigma_{\theta \theta} \frac{E_{\theta}}{r}+\Sigma_{\theta \theta} \frac{\partial E_{\theta}}{\partial r}+\frac{\Sigma_{\phi \phi}}{r} \frac{\partial E_{\phi}}{\partial \phi}\right]
\end{aligned}
$$

In equations (9), (10), and (11), $r$ is the radial distance from the pole and $E_{\theta}$ and $E_{\phi}$ are the latitudinal and longitudinal components of the ionospheric electric field, respectively. An inspection of these equations shows that $j_{\| H}$ comes from the contribution of the Hall current, and $j_{\| P 1}$ and $j_{\| P 2}$ come from the contribution of the Pedersen current. The major difference between the terms $j_{\| P 1}$ and $j_{\| P 2}$ is that the former is mainly determined by the gradient of the Pedersen conductance and the latter is mainly determined by the divergence of the electric field. We can see from equations (8) to (11) that when the ionospheric conductance is uniform, the field-aligned current will be solely closed to the Pedersen current even if the inclination of the geomagnetic field lines is included. In the following sections it will be seen that equations (8) to (11) are useful for studying the detailed features of the field-aligned current associated with the distorted two-cell convection pattern.

\subsection{Electric Potential and Conductivity}

The major object of this study is the field-aligned current associated with the distorted two-cell convection patterns for northward IMF conditions obtained from the DE 2 satellite data by Heppner and Maynard [1987]. The Heppner-Maynard convection model is an empirical model which uses the IMF condition as a criterion to group the data set and the model is based on a minimum number of characteristic patterns that represent typical electric field distributions. There are four convection patterns in the Heppner-Maynard model for northward IMF conditions, which are for $B y<0$ with a weakly or strongly northward $B_{z}$, and $B_{y}>0$ with a weakly or strongly northward $B_{z}$. In the following we only treat the case of strongly northward $B_{z}$ with $B_{y}<0$ and $B_{y}>0$. The published convection patterns in the Heppner and Maynard [1987] paper are a set of hand-drawn plots of the electrostatic potential which cannot be directly used in our modeling. Therefore we reproduced the Heppner-Maynard convection patterns for strongly northward IMF by using the functional representation of the model developed by Rich and Maynard [1989]. This functional representation was obtained by digitizing the Heppner-Maynard convection models and fitting a polynomial function to the digitized patterns.

The height-integrated Hall and Pedersen conductivities in our modeling are obtained from the ionospheric conductivity model developed by Rasmussen and Schunk [1987] and Rasmussen et al. [1988]. This model calculates ion densities in the $E$ and lower $F$ regions by numerically solving the chemical reaction equations for $\mathrm{N}_{2}^{+}, \mathrm{O}_{2}^{+}, \mathrm{O}^{+}$, and $\mathrm{NO}^{+}$. The ion densities are then used to calculate the Hall and Pedersen conductivities. Sources of ion production included in the conductivity model are solar EUV radiation, auroral precipitation, starlight, and resonantly scattered radiation. The conductivity model requires several inputs of which the day, date, universal time, $F_{10.7}-\mathrm{cm}$ flux, and the $A P$ index are needed to calculate the thermospheric densities [Hedin, 1983]. Also required for auroral production rates are the energy flux and characteristic energy of the precipitation. These auroral inputs are obtained from the empirical model of Spiro et al. [1982].

When the magnetospheric convection maps to the ionosphere, the associated current system can be significantly different for various ionospheric conductivity conditions. The major physical factors influencing the ionospheric conductivity are auroral precipitation, solar activity, and seasonal variations. In this work we focus on the variation of the current system caused by conductivity changes related to the above three factors. In the adopted conductivity model the auroral activity is binned according to the $A E$ index, the solar activity is binned according to the $F_{10.7}-\mathrm{cm}$ flux, and the seasonal effect is binned according to the input date. The parameters used in the conductivity model for various extreme conditions are as follows: $A E=1000$ is adopted for an active aurora and $A E=80$ for a quiet aurora; $F_{10.7}=250$ is for solar maximum and $F_{10.7}=70$ is for solar minimum; and December 22 is set for winter and June 23 is for summer.

\section{MODELING RESULTS}

The ionosphere in our simulation is modeled by computational grids on a polar coordinate system in which the radial dimension measures the latitude from $50^{\circ}$ to $90^{\circ}$ and the azimuthal dimension measures the longitude. The grid size is $1^{\circ}$ in latitude and $7.5^{\circ}$ in longitude. When the electric potential and conductivity are given, we can obtain solutions for the distributions of the field-aligned current and the ionospheric Hall and Pedersen currents by solving equations (1), (8), (9), (10), and (11). By using these solutions we can also study the closure of the field-aligned current with the Hall and Pedersen currents. To concentrate on the features associated with high-latitude convection, we eliminate the corotational electric field by simply setting it to zero. The border which separates the high-latitude electric field and the corotational electric field is assumed to be around $59^{\circ}$.

\subsection{Basic Features of the Current System}

Figure 1 shows the Heppner-Maynard convection models for strongly northward IMF conditions. Plots in the left column of Figure 1 show the convection pattern and electric field for the cases of $B_{y}<0$ and plots in the right column are for the case of $B_{y}>0$. Note that in both cases, strong electric fields and convection shears exist in the polar cap, which are different from what is obtained during southward IMF conditions. For $B_{y}<0$ a strong shearing flow exists around $75^{\circ}$ in the noon sector, while for $B y>0$, a strong shearing flow exists around $73^{\circ}$ in the morning sector.

Figures 2 and 3 show the cases in which the ionospheric conductivity is appropriate for winter time, quiet aurora, and 

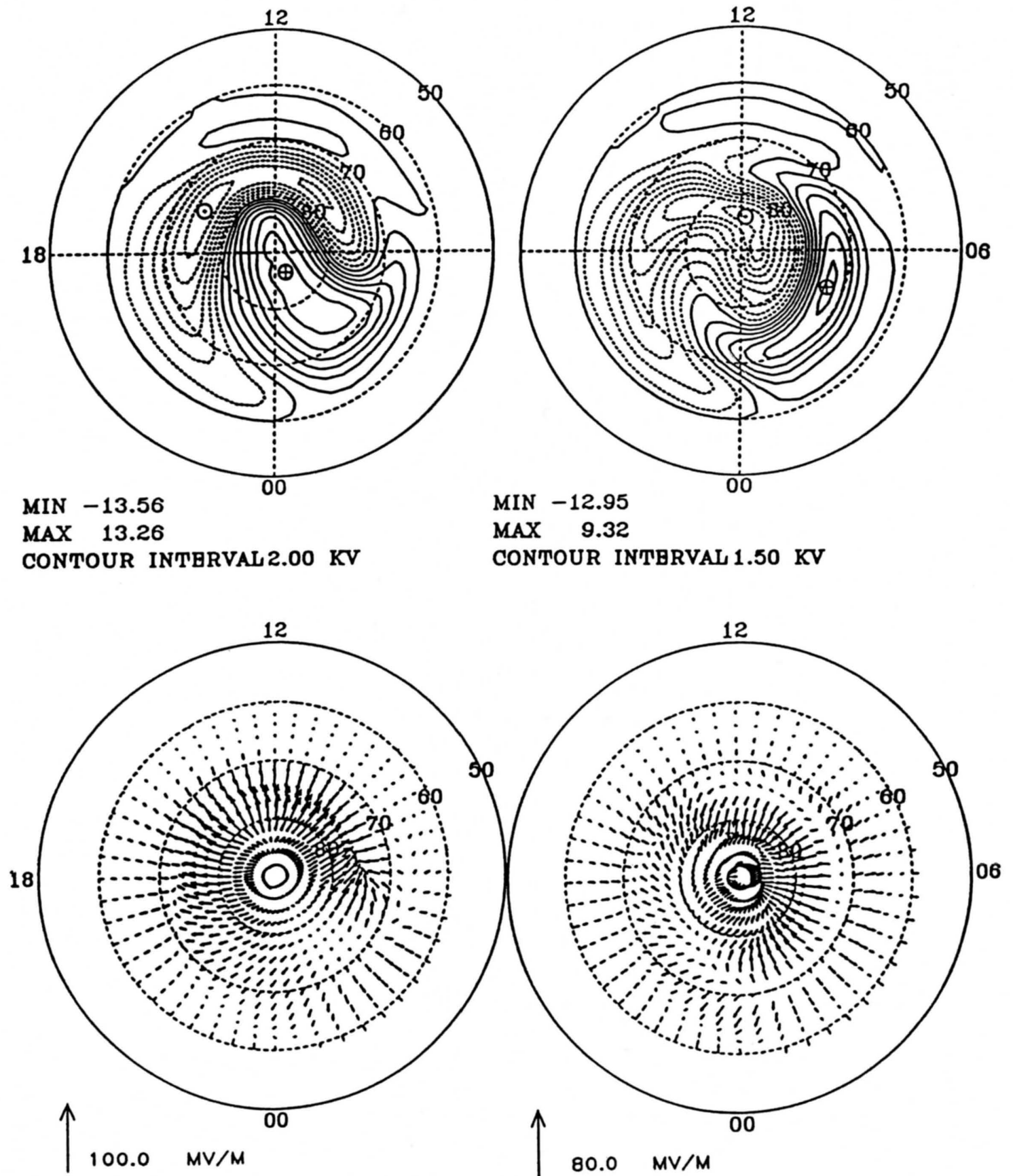

Fig. 1. Electric potential and electric field distributions from the Heppner and Maynard [1987] convection model for strongly northward IMF with a negative $B_{y}$ (left column) and with a positive $B_{y}$ (right column).

solar maximum conditions. Figure 2 shows the case of $B_{y}<0$ with a strong northward $B_{z}$. The top left panel of Figure $2 a$ shows the integrated Hall conductivity in which the ionization effects of EUV radiation, auroral precipitation, starlight, and resonantly scattered radiation have been included. The top right panel of Figure $2 a$ shows the field-aligned current distribution associated with the distorted two-cell convection pattern for $B_{y}<0$. The dashed lines are for upward fieldaligned currents, and the solid lines are for downward fieldaligned currents. The region 1 and 2 current systems can be seen in the plot. The most important thing to note is the existence of the NBZ current in the polar cap. The maximum intensity of the upward NBZ current is about $0.37 \mu \mathrm{A} / \mathrm{m}^{2}$ and the maximum intensity of the downward NBZ current is about $0.44 \mu \mathrm{A} / \mathrm{m}^{2}$. The clear appearance of the NBZ current in this result suggests that the NBZ current can be associated with the distorted two-cell convection pattern for northward IMF conditions.

The bottom left panel of Figure $2 a$ shows the ionospheric horizontal current. Instead of the strong westward and eastward electrojets in the evening-midnight sector, which are typical for a southward IMF condition, the strong shear between an eastward and a westward current can be seen in the noon sector. The bottom right panel of Figure $2 a$ shows the distribution of $j_{\| H}$, which reflects the contribution of the divergence of the Hall current. The left panel of Figure $2 b$ shows the distribution 

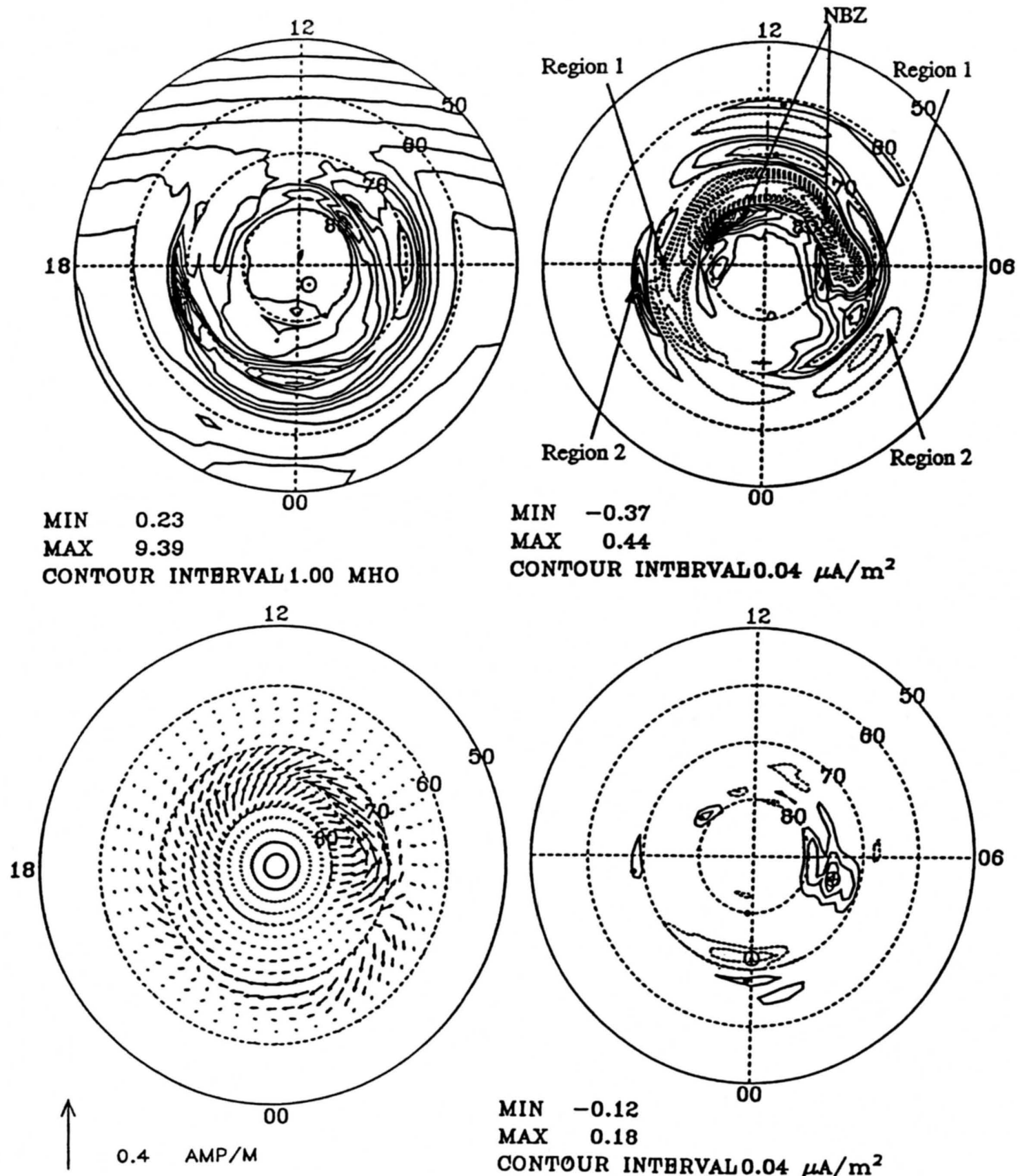

Fig. 2a. (top left panel) Input ionospheric Hall conductance for winter, quiet aurora, and solar maximum, (top right panel) total field-aligned current, (bottom left panel) ionospheric horizontal current, and (bottom right panel) the field-aligned current connecting to the Hall current. In the plots of field-aligned current the dashed lines denote the upward field-aligned currents and the solid lines denote the downward field-aligned currents. The IMF for this case has a strongly northward $B_{z}$ and a negative $B_{\boldsymbol{y}}$.

of the Joule heating rate, in which a strong heating can be seen on the dayside. The right panel of Figure $2 b$ shows the distribution of the sum of $j_{\| P 1}$ and $j_{\| P 2}$, which reflects the contribution of the divergence of the Pedersen current. As can be seen, the contribution of the Hall current to the fieldaligned current is very small compared to that of the Pedersen current, especially on the dayside. This suggests that the fieldaligned current during northward IMF is mainly closed by the Pedersen current. Later, we will show that this is true in most of the situations, except in the strong auroral precipitation regions.
Figure 3 shows the case of $B_{y}>0$ with a strongly northward $B_{z}$. The top left panel of Figure $3 a$ shows the Hall conductance distribution. The top right panel of Figure $2 a$ shows the distribution of the field-aligned current from which a complete pattern of the region 1 , region 2 , and NBZ currents, with a relatively weak downward NBZ current, can be clearly seen. The bottom left panel of Figure $3 a$ shows the ionospheric horizontal current. It differs from the case of $B_{y}<0$, in that a strong shearing of an eastward and a westward current appears in the morning sector when $B_{y}>0$ instead of in the noon sector. The bottom right panel of Figure $3 a$ shows the 


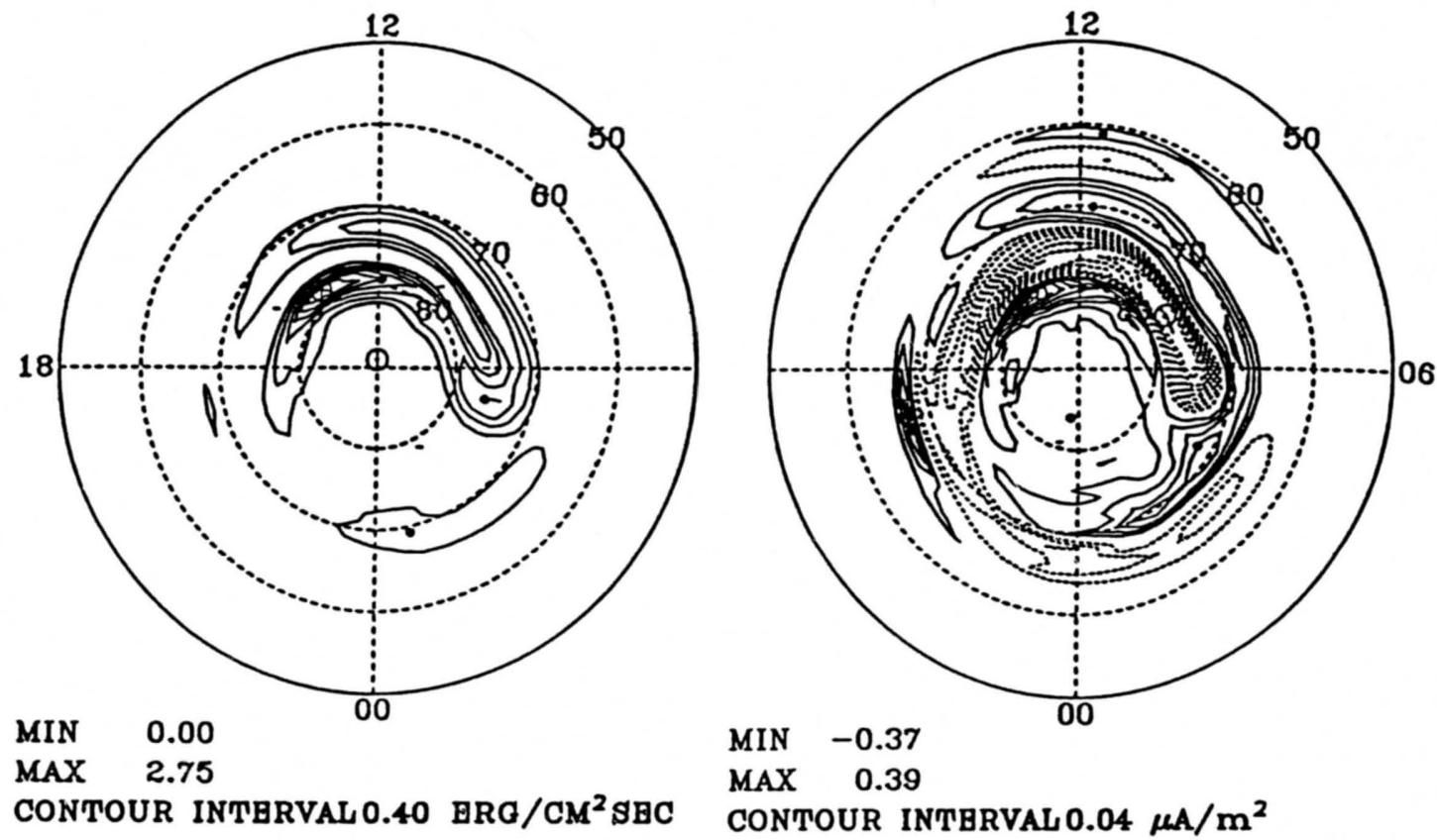

Fig. $2 b$. The continuance of the case shown in Figure $2 a$, which shows (left panel) the distribution of Joule heating rate, and (right panel) the field-aligned current connecting to the Pedersen current.

distribution of $j_{\| H}$, which indicates that the Hall current is almost divergence-free. The left panel of Figure $3 b$ shows the distribution of the Joule heating rate. Note that as $B_{y}$ becomes positive, the strongest heating region shifts from the noon sector to the morning sector. Finally, the right panel of Figure $3 b$ shows the contribution of the Pedersen current to the field-aligned current. This pattern is very similar to the pattern of the total field-aligned current.

A few important points should be noted here. By using the same convection patterns for a strong positive $B_{z}$ and a conductivity distribution for equinox and solar minimum, Rich and Maynard [1989] found that for $B y<0$, the field-aligned current system did not contain either an NBZ current or the region 2 current on the eveningside, while for $B_{y}>0$, only a set of dayside region 1 currents were found. Obviously, their results are considerably different from our results shown in Figures 2 and 3. On the basis of their results, Rich and Maynard [1989] concluded that the existence of a strong NBZ current system might require a different convection pattern from that represented by the Heppner-Maynard model and that the NBZ current system does not represent the high-latitude configuration during many periods of northward IMF. To resolve this issue, we checked the detailed features of how the field-aligned current systems shown in Figures 2 and 3 close to the horizontal currents in terms of equations (8) to (11) and found that $j_{\| P 1}$ can substantially contribute to both the region 2 and the NBZ currents missing in Rich and Maynard's [1989] results. This indicates that the calculated field-aligned current is very sensitive to the matching or mismatching between the conductivity gradient and the electric field. Even if the same convection pattern is used, different ionospheric conditions can lead to field-aligned current systems with substantially different features. Therefore on the basis of our results, we believe that the NBZ current system can be associated with the distorted two-cell convection pattern presented by Heppner and Maynard [1987] and is a prominent current system for northward IMF conditions.
Such a conclusion is consistent with the modeling results presented by Rasmussen and Schunk [1988]. Starting from the field-aligned current distribution deduced from Magsat satellite data [Iijima and Shibaji, 1987] which had the NBZ current feature, and the USU conductivity model [Rasmussen and Schunk, 1988], they calculated possible convection patterns for specific ionospheric conditions. They found that the convection pattern can be very similar to the distorted two-cell pattern presented by Heppner and Maynard [1987], depending on how the missing field-aligned currents were closed on the dayside. We find that the sense of the connection between the region 1 upward field-aligned current and the NBZ current assumed in their modeling is consistent with that shown in Figure 2. Our results indicate that such a field-aligned current crossing the noon meridian plays an important role in determining the basic feature of the ionospheric convection.

In summary, the field-aligned current distributions shown in Figures 2 and 3 are consistent with the field-aligned current system obtained from the Magsat satellite [Iijima and Shibaji, 1987]. On the basis of such a consistency and also considering that the Magsat data missed the dayside region below $80^{\circ}$, which plays an important role in determining the basic feature of convection, we suggest that the current system presented by Iijima and Shibaji [1987] which is normally used by people as evidence of four-cell convection, might imply a distorted two-cell convection pattern. This suggestion is consistent with Rasmussen and Schunk's [1988] results, except utilizing a different approach.

From our modeling results we also found that the regions of the upward NBZ current associated with a distorted two-cell convection pattern are well overlapped by the regions where $\nabla \cdot \mathbf{E}<0$. It has been pointed out by Lyons [1980] that the existence of a potential drop structure along magnetic field lines requires $\nabla \cdot \mathbf{E}<0$. The coincidence of the regions where $\nabla \cdot \mathbf{E}<0$ and the upward NBZ current locations suggests that the intensive upward NBZ current during northward IMF is related to the existence of the potential drop along the 

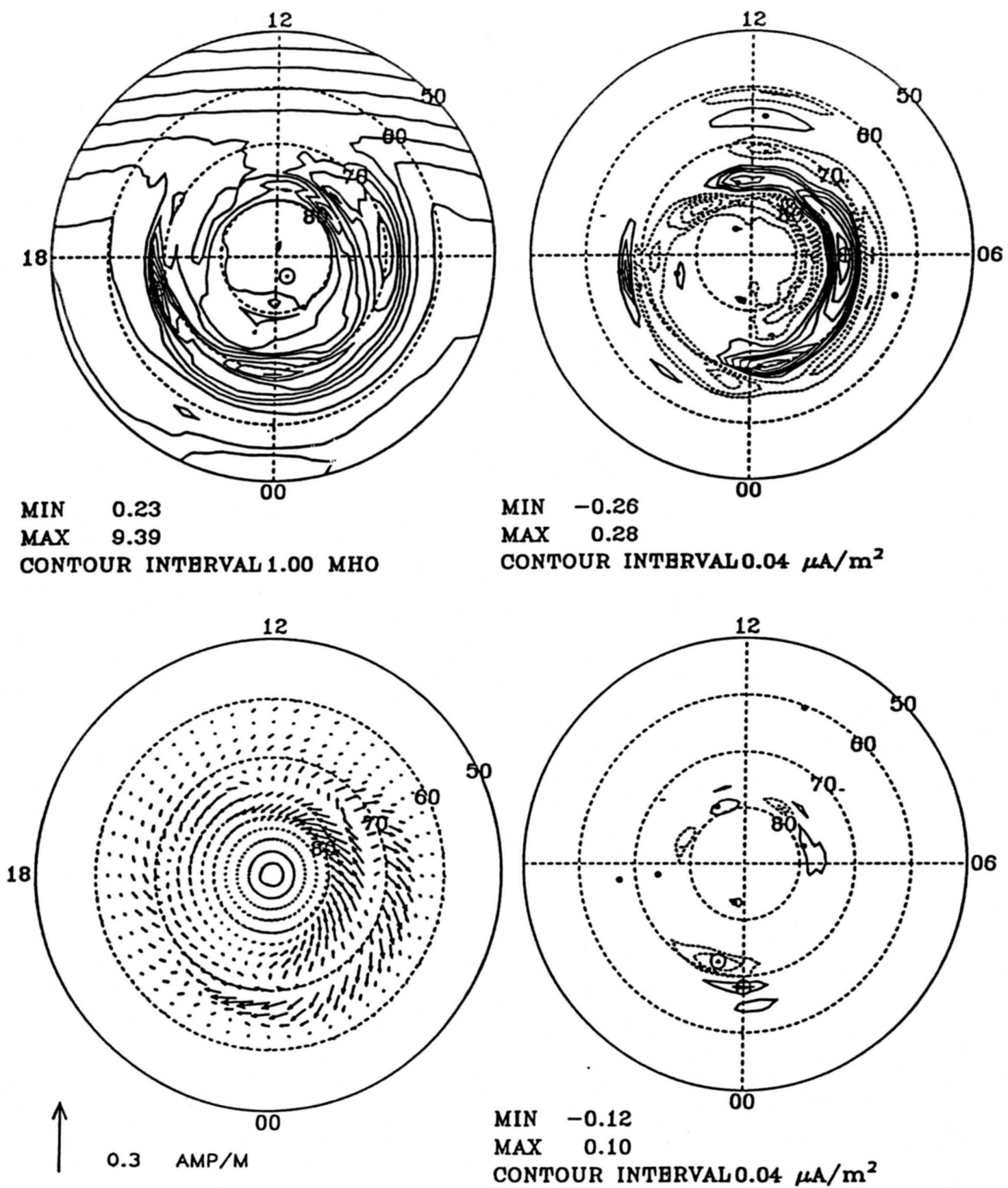

Fig. 3a. (top left panel) Input ionospheric Hall conductance for the same geophysical conditions as for Figure $2 a$, (top right panel) total field-aligned current (bottom left panel) ionospheric horizontal current, and (bottom right panel) the field-aligned current connecting to the Hall current. The IMF for this case has a strongly northward $B_{z}$ and a positive $B_{y}$.

geomagnetic field lines. Furthermore, because the intensive upward field-aligned current and the negative space charge, $\nabla \cdot \mathbf{E}<0$, are associated with the occurrence of auroras in the polar cap [Lyons, 1980; Burke et al., 1982; Chiu and Gorney, 1983], our results also suggest that the regions of the intensive upward NBZ current associated with a distorted twocell convection pattern in our modeling are the regions where the polar cap auroras occur.

On the basis of the above results and also considering the transition between the two cases shown in Figures 2 and 3 we suggest the following. The distorted two-cell ionospheric convection pattern is a dominant pattern for most of the northward IMF conditions. The NBZ current system is a prominent current system during northward IMF and is associated with the distorted two-cell convection for most of the ionospheric conditions. A four-cell convection pattern is most likely to occur when the direction of the IMF is due north or very close to the north. The last suggestion is supported by the observational results of Clauer and Friis-Christensen [1988] and the theoretical predictions of Zhu and Kan [1990].

In the following subsections we discuss a systematic study we conducted of the influences of the seasonal variation, the auroral activity, and the solar variation on the field-aligned current associated with the distorted two-cell convection pattern. To avoid being lengthy, we only show the cases for $B_{y}<0$ with various ionospheric conductivity conditions. We 


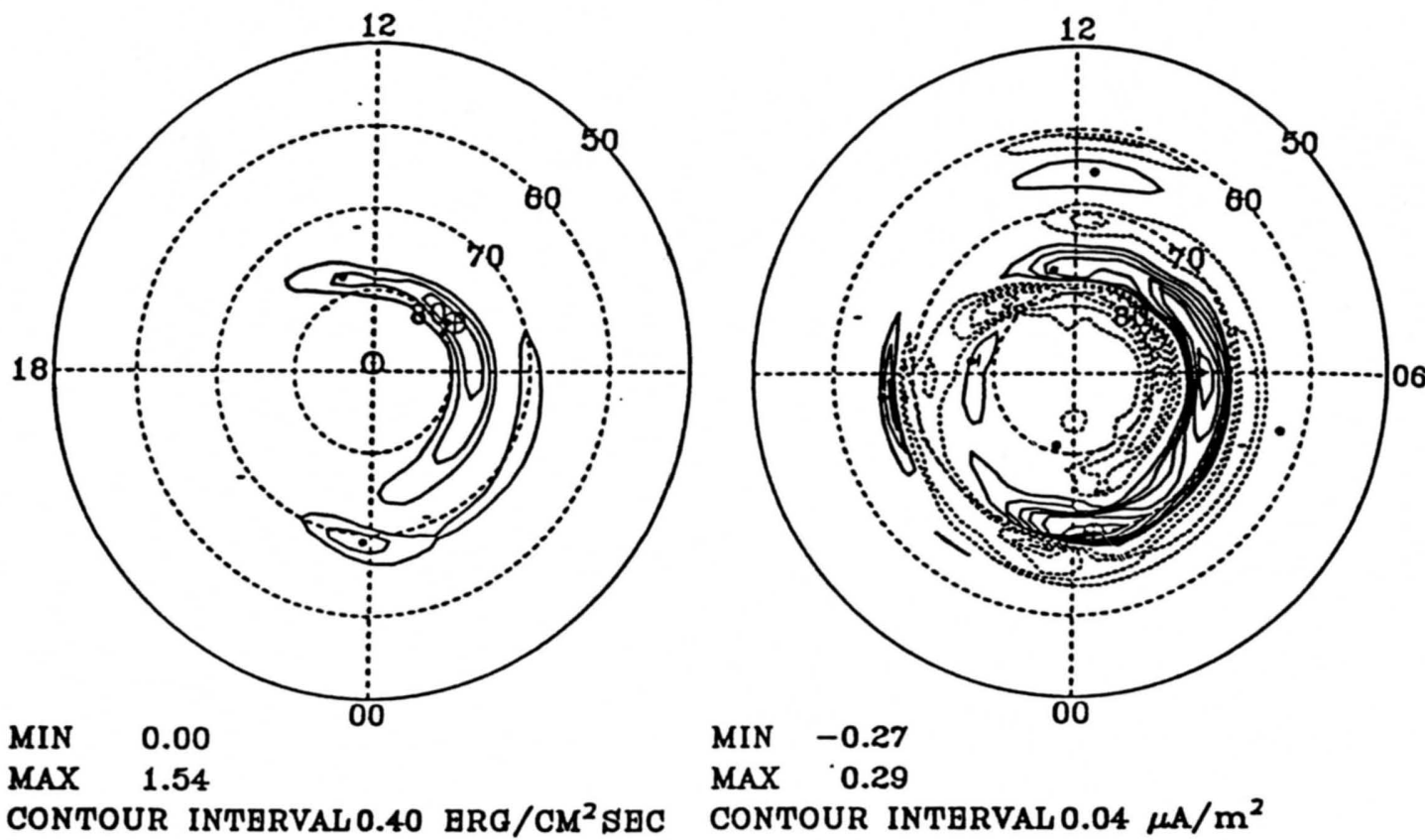

Fig. 3b. The continuance of the case shown in Figure $3 a$, which shows (left panel) the distribution of Joule heating rate, and (right panel) the field-aligned current connecting to the Pedersen current.

use the case shown in Figure 2 as a base and change one parameter at a time to see the various effects.

\subsection{Seasonal Variation}

The condition for the ionospheric conductance shown in Figure 2 is winter time, quiet aurora and solar maximum. To see the seasonal effect, we use a conductivity distribution for the summer time with the same auroral and solar conditions as that for Figure 2. The resulting conductance distribution is shown in the top left panel of Figure 4. A comparison of Figures 2 and 4 indicates that there is a significant difference related to the seasonal variation. In the summer time the conductance on the nightside and in the polar cap is greatly enhanced by the EUV radiation. Such a conductivity enhancement can greatly charge the conductivity gradient in those regions. As previousiy mentioned, the field-aligned current is sensitive to the matching or mismatching between the conductivity gradient and the convection electric field; therefore a significant change in the field-aligned current distribution can be expected in going from winter to summer conditions.

The resulting field-aligned current distribution for the summer time is shown in the top right panel of Figure 4 . The bottom left panel and the bottom right panel of Figure 4 show the distributions of the horizontal current and $j_{\| H}$, respectively. From the comparison of Figures 2 and 4 it can be seen that during the summer time the field-aligned current in the dayside polar cap is greatly enhanced and also the whole field-aligned current system expands to higher latitudes. The maximum intensity of the NBZ current during the summer time is almost 2 times greater than that during the winter time. Also, the horizontal current and Joule heating are greatly enhanced during the summer time, mainly in the polar cap and the dayside regions. An interesting feature found in our results is that the increase of the field-aligned current intensity in the polar cap during the summer time is exclusively due to the increasing contribution from $j_{\| P 2}$, which is mainly related to the term $\Sigma_{p} \nabla \cdot \mathbf{E}$. In contrast, the divergence of the Hall current becomes even smaller, although the Hall conductance is larger during the summer time. In other words, such a result indicates that during the summer time, more field-aligned currents close to the Pedersen current instead of closing to the Hall current, especially in the polar cap. The following simple explanation can be given for such a result. During the summer time the EUV radiation can greatly enhance the conductivity in the polar cap, but it can also smooth the conductivity gradient. Since the divergence of the Hall current critically depends on the conductivity gradient, a smaller conductivity gradient can lead to less field-aligned currents being closed to the Hall current. On the other hand, for the same convection pattern a more conducting ionosphere in the summer time requires more field-aligned current to flow between the magnetosphere and ionosphere. Consequently, the only way for this to occur is that more field-aligned currents close to the Pedersen current in the summer time.

\subsection{Auroral Activity}

Figure 5 shows the case where the ionospheric conductivity is governed by winter time, active aurora, and solar maximum conditions. This case should be considered as an extreme conductivity enhancement that is used in order to determine the maximum effect on the field-aligned current. Typically, active auroral conditions are not likely to occur during a strong northward IMF. The top left panel of Figure 5 shows the Hall conductance distribution in which the enhanced conductance around the oval is due to auroral precipitation. The top right panel shows the field-aligned current, and the bottom panels show the horizontal current and the distribution of $j_{I H}$. From the comparison of Figures 2 and 5 we see that the variation of aurora-related conductivity can also significantly influence the field-aligned current associated with the distorted two-cell convection pattern. During strong aurora! activity the field- 

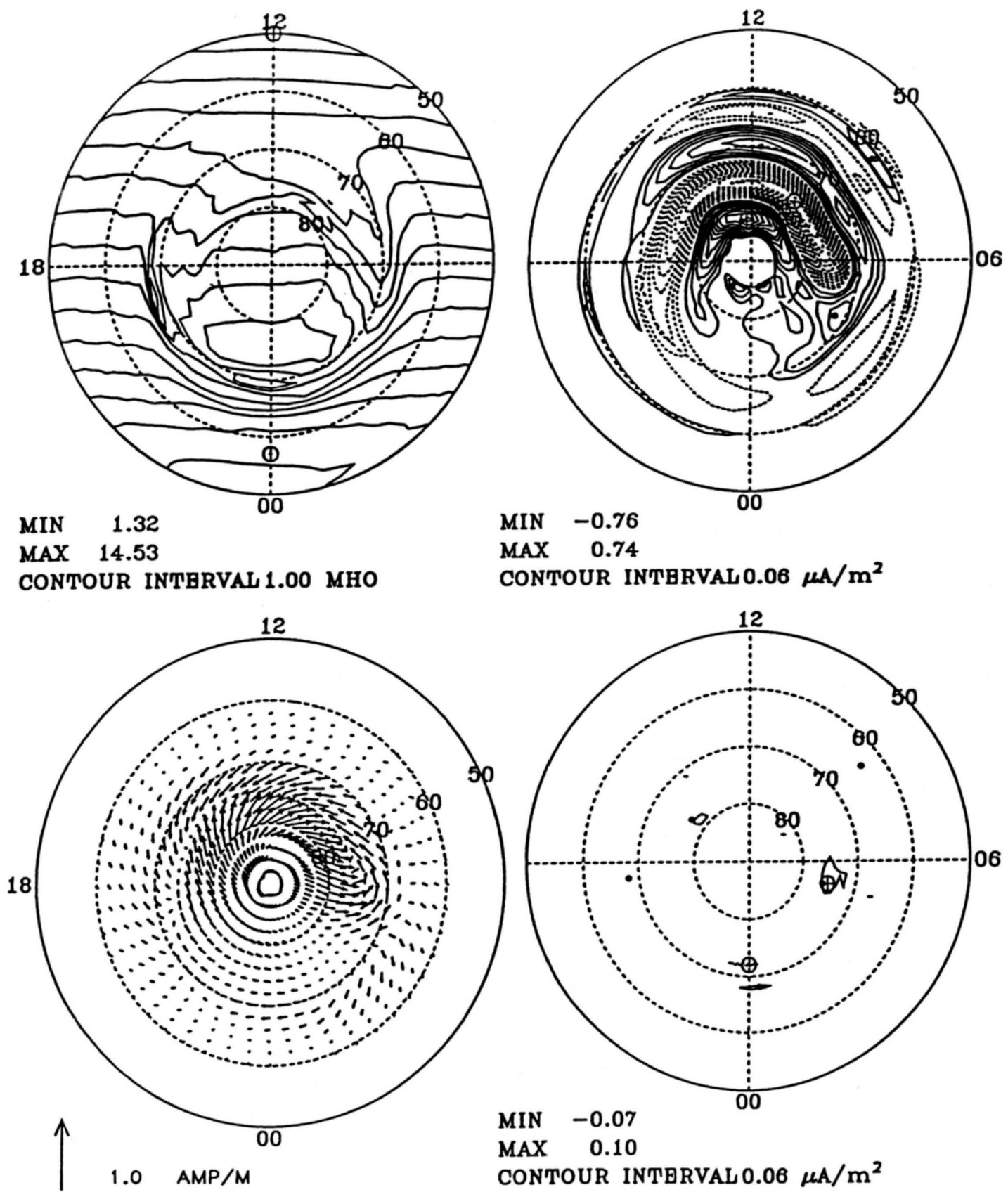

Fig. 4. (top left panel) Input ionospheric Hall conductance for summer, quiet aurora, and solar maximum, (top right panel) total field-aligned current (bottom left panel) ionospheric horizontal current, and (bottom right panel) the field-aligned current connecting to the Hall current. The IMF for this case has a strongly northward $B_{z}$ and a negative $B_{y}$. A comparison of this case and Figure 2 shows the seasonal effects on the field-aligned current.

aligned current in the oval and on the nightside is much stronger than that during quiet aurcra periods. We also found that the eastward and westward electrojets in the eveningmidnight sector are substantially incieased and that there is strong Joule heating in the oval during the time of active aurora.

From the plot of $j_{\| H}$ in Figure 5 a careful reader can find that in the oval, especially in the upward region 1 current area in the evening-midnight sector, the Hall current is no longer almost divergence-free. It is found that the large increase of the field-aligned current in the oval and the evening-midnight sector during the time of active auroral conditions is mainly due to the increasing contribution from the Hall current. In other words, during the active aurora period the intensive aurora-related field-aligned current mainly closes to the Hall current instead of the Pedersen current. An explanation for such a feature is as follows. The conductivity enhancement caused by auroral precipitation is on a relatively small scale and is locally concentrated. Therefore in addition to the increase of the conductivity itself the conductance gradient can also greatly increase. Since the divergence of the Hall current critically depends on the conductance gradient, a larger gradient can lead to more field-aligned currents being closed to the Hall current. 

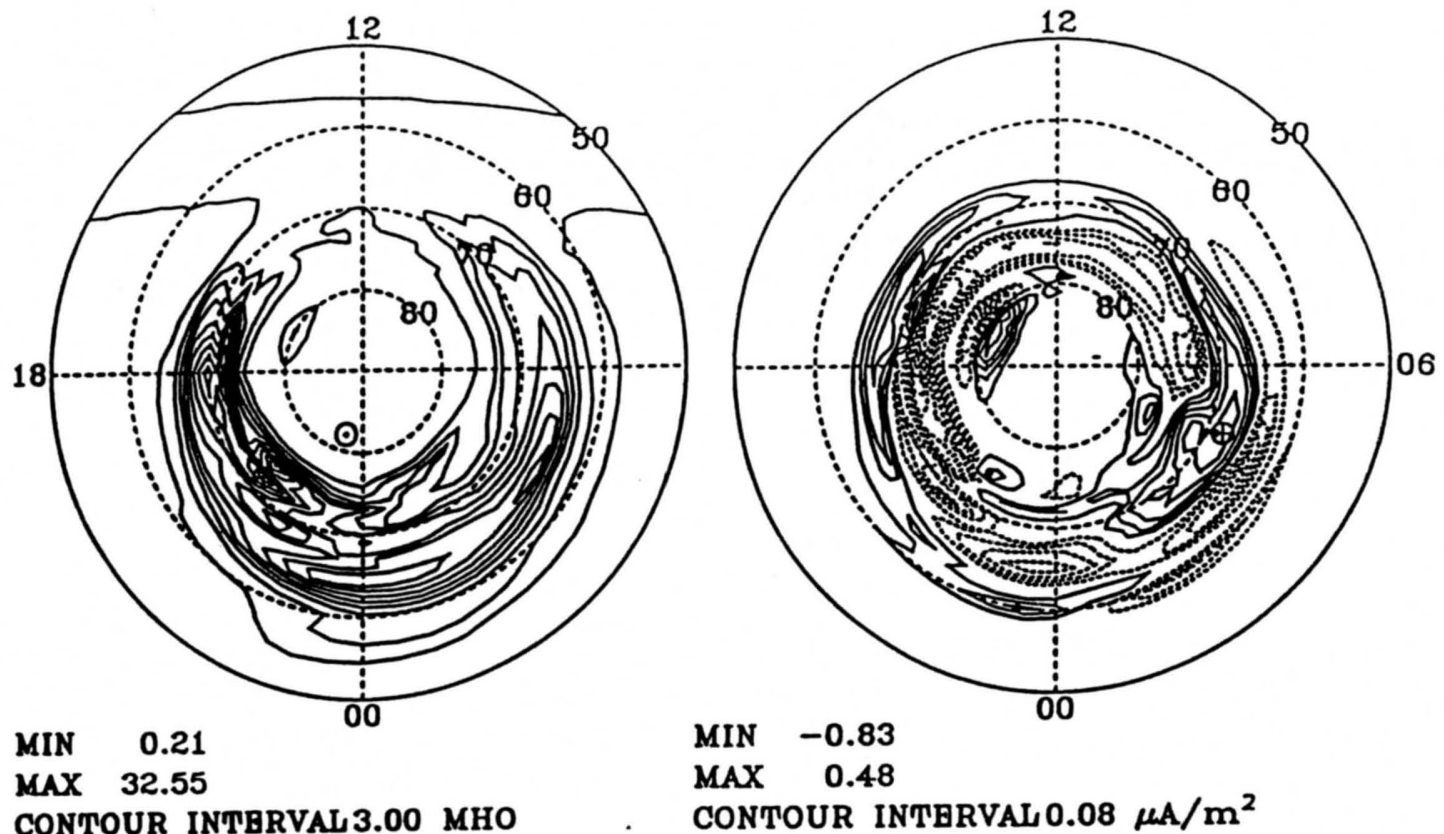

\section{MAX 32.55 CONTOUR INTERVAL 3.00 MHO}

CONTOUR INTERVAL $0.08 \mu \mathrm{\mu A} / \mathrm{m}^{2}$

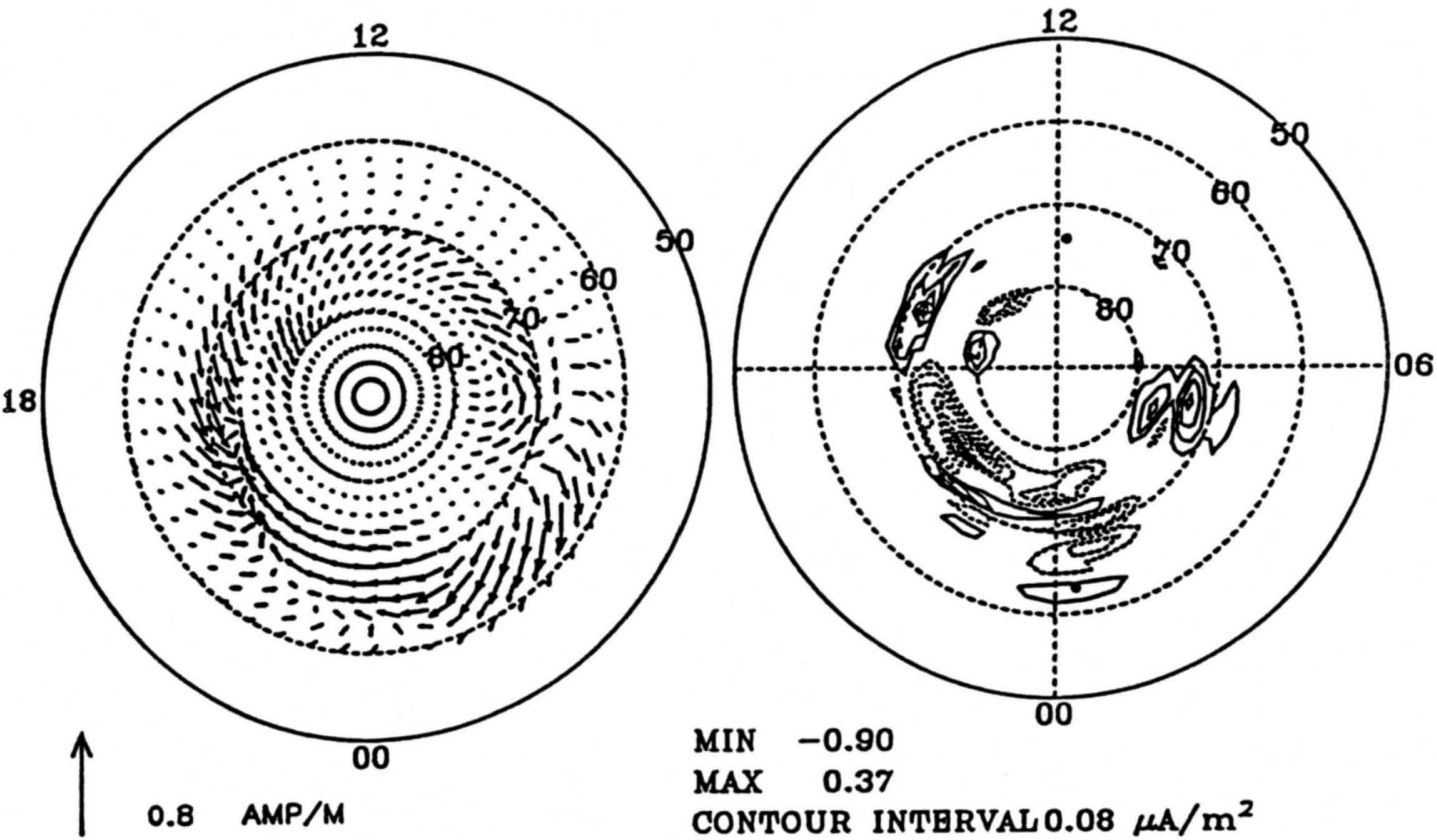

Fig. 5. (top left panel) Input ionospheric Hall conductance for winter, active aurora, and solar maximum, (top right panel) total field-aligned current (bottom left panel), ionospheric horizontal current, and (bottom right panel) the field-aligned current connecting to the Hall current. The IMF for this case has a strongly northward $B_{z}$ and a negative $B_{y}$. A comparison of this case and Figure 2 shows the effects of the auroral activity on the field-aligned current.

In conclusion, the increase of the field-aligned current in the polar cap in the summer time is mainly due to the increasing contribution from the Pedersen current, while the increase of the field-aligned current in the oval and in the eveningmidnight sector during the active aurora periods is mainly due to the increasing contribution from the Hall current.

\subsection{Solar Variation}

We also ran a few cases to study the effects of the solar variation on the field-aligned current during northward IMF, but the plots are not shown in this paper. It was found that the solar variation has its impact mainly on the intensity of the field-aligned current, not the pattern, that is associated with a distorted two-cell convection pattern. A larger $F_{10.7}$ during solar maximum leads to a stronger field-aligned current system. In the summer time the intensity change of fieldaligned current due to the solar variation can be up to $30-40 \%$, but in the winter the corresponding change is less than $5 \%$. It was also found that during solar maximum, less field-aligned current closes to the Hall current. This is because a larger $F_{10.7}$ tends to smooth the local gradient of conductivity, thereby reducing the contribution of the Hall current to the field-aligned current. 


\section{SUMMARY AND CONCLUSION}

By using the Heppner-Maynard convection model [Heppner and Maynard, 1987; Rich and Maynard, 1989] and the Utah State University conductivity model [Rasmussen and Schunk, 1987; Rasmussen et al., 1988] a systematic study has been conducted of the influence of the ionospheric conductance on the field-aligned current associated with the distorted two-cell convection pattern for northward IMF. This is the first time that a complete set of global field-aligned current systems covering the dayside region below $80^{\circ}$ has been presented for various ionospheric conductivity conditions and northward IMF. Our results show that the variation of the ionospheric conductivity distribution can significantly affect the features of the field-aligned current for northward IMF, where the matching or mismatching between the conductance gradient and the convection electric field plays a key role.

The NBZ current is a prominent feature during northward IMF. Whether or not the NBZ current is associated with the distorted two-cell convection pattern is an essential question in the controversial four-cell versus two-cell issue. Our modeling results indicate that the NBZ current system can be associated with the distorted two-cell pattern during northward IMF. Furthermore, on the basis of the consistency between our calculated field-aligned current systems and those deduced from the Magsat satellite data [Iijima and Shibaji, 1987], and also considering that the Magsat data missed the dayside region below $80^{\circ}$, we suggest that the current system presented by Iijima and Shibaji [1987] for northward IMF, which is normally used by people as evidence of four-cell convection, might imply a distorted two-cell convection pattern. Our results have shown that the field-aligned current crossing the noon meridian, which is a confused region for a four-cell convection pattern, plays an important role in determining the basic feature of the ionospheric convection pattern. The importance of the current in this region has also been pointed out by Rasmussen and Schunk [1988]. We also propose that a four-cell convection is most likely to occur when the direction of the IMF is due north or very close to the north. Similar proposals have been presented by Clauer and Friis-Christensen [1988] based on observational results and by Zhu and Kan [1990] based on a theoretical study.

The conductivity variation related to seasonal changes and auroral activity can significantly affect the field-aligned current system associated with a distorted two-cell convection pattern. We found that during the summer time the fieldaligned current in the dayside polar cap is greatly enhanced and the whole field-aligned current system expands to higher latitudes. The maximum intensity of the NBZ current during the summer time can almost be 2 times greater than that during the winter time. The horizontal current and Joule heating are also greatly enhanced during the summer time, mainly in the polar cap and on the dayside. During active aurora periods the field-aligned current in the oval and on the nightside is much stronger than that during quiet aurora periods, and the eastward and westward electrojets in the evening-midnight sector are substantially increased.

To get a better understanding of the current closure characteristics associated with a distorted two-cell convection pattern, we also looked into the details of how the fieldaligned current closes to the Hall and Pedersen currents. We found that the field-aligned current associated with a distorted two-cell convection pattern closes mainly to the Pedersen current and the Hall current is almost divergence-free. This is true for most of the ionospheric conditions we considered, except in the strong auroral precipitation regions. The results show that the increase of the field-aligned current in the polar cap during the summer time is mainly due to the increasing contribution from the Pedersen current, and the increase of the field-aligned current in the oval region and in the eveningmidnight sector during the active aurora periods is mainly due to the increasing contribution from the Hall current. The divergence of the Hall current is smaller in summer, even though the Hall conductance is larger.

From the modeling results we found that the upward NBZ current associated with a distorted two-cell convection pattern locates in the regions where $\nabla \cdot \mathbf{E}<0$. This suggests that the intensive upward NBZ current during northward IMF can be related to the existence of the potential drop structure along the geomagnetic field lines and the polar cap auroras are associated with these intensive upward NBZ currents. We also found that the solar cycle variation of the conductivity has its impact mainly on the intensity of the field-aligned current but not the pattern. A larger $F_{10.7}$ during solar maximum leads to a stronger field-aligned current system. The variation of the current intensity due to the solar cycle variation can be up to $30-40 \%$ during the summer time and is less than $5 \%$ during the winter time.

The four-cell versus distorted two-cell convection patterns during northward IMF is still a controversial issue. On the basis of our modeling results we propose the following: The distorted two-cell ionospheric convection pattern is the dominant pattern for most of the northward IMF conditions. The NBZ current system is a prominent current system during northward IMF and can be associated with the distorted twocell convection pattern for most of the ionospheric conditions. A four-cell convection pattern is most likely to occur when the direction of the IMF is due north or very close to the north. A theta aurora might be associated with a fourcell convection, although this case was not considered in this study.

Acknowledgments. This research was supported by NASA grant NAG5-1484, grant AFOSR-90-0026, and NSF grant ATM-89-13230 to Utah State University.

The Editor thanks P. L. Rothwell and another referee for their assistance in evaluating this paper.

\section{REFERENCES}

Burch, J. L., P. H. Reiff, J.D. Menietti, R. A. Heelis, W. B. Hanson, S. D. Shawhan, E. G. Shelley, M. Sugiura, D. R. Weimer, and J. D. Winningham, IMF $B_{y}$-dependent plasma flow and Birkeland currents in the dayside magnetosphere, 1, Dynamics Explorer observations, J. Geophys. Res., 90, 1577, 1985.

Burke, W. J., M. C. Kelley, R. C. Sagalyn, M. Smiddy, and S. T. Lai, Polar cap electric field structures with a northward interplanetary magnetic field, Geophys. Res. Lett., 6, 21, 1979.

Burke, W. J., M. S. Gussenhoven, M. C. Kelley, D. A. Hardy, and F. J. Rich, Electric and Magnetic field characteristics of discrete arcs in the polar cap, J. Geophys. Res., 87, 2431, 1982.

Chiu, Y. T., and D. J. Gomey, Eddy intrusion of hot plasma into the polar cap and formation of polar-cap arcs, Geophys. Res. Lett., 10, 463, 1983.

Chiu, Y. T., Formation of polar cap arcs, Geophys. Res. Lett., 16, 743, 1989.

Clauer, C. R., and E. Friis-Christensen, High-latitude electric fields and currents during strongly northward interplanetary magnetic field: Observations and model simulations, J. Geophys. Res., 93, 2749, 1988. 
Dungey, J. W., Interplanetary magnetic field and the auroral zones, Phys. Rev. Lett., 6, 47, 1961.

Frank, L. A., J. D. Craven, J. L. Burch, and J. D. Winningham, Polar views of the Earth's aurora with Dynamics Explorers, Geophys. Res. Lett., 9, 1001, 1982.

Gussenhoven, M. S., Extremely high latitude auroras, J. Geophys. Res., 87, 2401, 1982.

Hardy, D. A., W. J. Burke, and M. S. Gussenhoven, DMSP optical and electron measurements in the vicinity of polar cap arcs, J. Geophys. Res., 87, 2413, 1982.

Hardy, D. A., M. S. Gussenhoven, R. Raistrick, and W. J. McNeil, Statistical and functional representations of the patterns of auroral energy flux, number flux and conductivity, J. Geophys. Res., 92, 12,275, 1987.

Hedin, A. E., A revised thermospheric model based on mass spectrometer and incoherent scatter data: MSIS-83, J. Geophys. Res., 88, 10,170, 1983.

Heelis, R. A., J. K. Lowell, and R. W. Spiro, A model of the highlatitude ionospheric convection pattem, J. Geophys. Res., 87, 6339, 1982.

Heppner, J. P., and N. C. Maynard, Empirical high-latitude electric field models, J. Geophys. Res., 92, 4467, 1987.

Iijima, T., and T. Shibaji, Global characteristics of northward IMFassociated (NBZ) field-aligned currents, J. Geophys. Res., 92, 2408, 1987.

Iijima, T., T. A. Potemra, L. J. Zanetti, and P. F. Bythrow, Large-scale Birkeland currents in the dayside polar region during strongly northward IMF: A new Birkeland current system, J. Geophys. Res., 89, 7441, 1984.

Ismail, S., and C.-I. Meng, A classification of polar cap auroral arcs, Planet. Space Sci., 30, 319, 1982.

Kan, J. R., and W. J. Burke, A theoretical model of polar cap auroral arcs, J. Geophys. Res., 90, 4171, 1985.

Lassen, K., On the classification of high-latitude auroras, Geophys. Norv., 29, 87, 1972.

Lyons, L. R., Generation of large-scale regions of auroral currents, electric potentials, and precipitation by the divergence of the convection electric field, J. Geophys. Res., 85, 17, 1980.

Maezawa, K., Magnetic convection induced by the positive and negative $z$ components of the interplanetary magnetic field: Quantitative analysis using polar cap magnetic records, J. Geophys. Res., 81, 2289, 1976.

Murphree, J. S., C. D. Anger, and L. L. Cogger, The instantaneous relationship between polar cap and oval auroras at times of northward interplanetary magnetic field, Can. J. Phys., 60, 349,
1982 .

Potemra, T. A., L. J. Zanetti, P. F. Bythrow, A. T. Y. Lui, and T. Iijima, $B$-dependent convection patterns during northward interplanetary magnetic field, J. Geophys. Res., 89, 9753, 1984.

Reiff, P. H., and J. L. Burch, IMF $B_{y}$-dependent dayside plasma flow and Birkeland currents in the dayside magnetosphere, 2, A global model for northward and southward IMF, J. Geophys. Res., 90, 1595, 1985.

Rich, F. J., and N. C. Maynard, Consequences of using simple analytical functions for the high-latitude convection electric field, J. Geophys. Res., 94, 3687, 1989.

Rich, F. J., M. S. Gussenhoven, and M. E. Greenspan, Using simultaneous particle and field observations on a low altitude satellite to estimate Joule heat energy flow into the high-latitude ionosphere, Ann. Geophys., 5A (6), 527, 1987.

Rasmussen, C. E., and R. W. Schunk, Ionospheric convection driven by NBZ currents, J. Geophys. Res., 92, 4491, 1987.

Rasmussen, C. E., and R. W. Schunk, Ionospheric convection inferred from interplanetary magnetic field-dependent Birkeland currents, $J$. Geophys. Res., 93, 1909, 1988.

Rasmussen, C. E., R. W. Schunk, and V. B. Wickwar, A photochemical equilibrium model for ionospheric conductivity, J. Geophys. Res., 93, 9831, 1988.

Russell, C. T., The configuration of the magnetosphere, in Critical Problems of Magnetospheric Physics, edited by E. R. Dyer, pp. 116, IUCSTP, National Academy of Sciences, Washington, D. C., 1972.

Spiro, R. W., P. H. Reiff, and L. J. Maher, Jr., Precipitating electron energy flux and auroral zone conductances: An empirical model, $J$. Geophys. Res., 87, 8215, 1982.

Zhu, L., and J. R. Kan, Relationship between four-cell and distorted two-cell convection pattems during northward IMF, Geophys. Res. Lett., 17, 2325, 1990.

L. Zhu, R. W. Schunk, and J. J. Sojka, Center for Atmospheric and Space Sciences, Utah State University, Logan, Utah 84322-4405.

(Received April 1, 1991; revised June 3, 1991; accepted July 2, 1991.) 